\title{
Impacts of weir removal on channel dynamics in non-uniform sediment beds
}

\author{
Hao Zhang*, Yasunori Muto**, Shiro Nakanishi*** and Hajime Nakagawa**** \\ * Member, Dr. of Eng., Assist. Prof., Disaster Prevention Research Institute, Kyoto Univ. (Yoko-oji, Fushimi, Kyoto 612-8235) \\ ** Member, Ph. D, Prof., Dept. of Civil and Envi. Eng., Univ. of Tokushima (Tokushima 770-8506) \\ *** Graduate School of Civil and Earth Resources Eng., Kyoto Univ. (Kyouto-Daigaku Katsura, Nishikyo, Kyoto 615-8510) \\ **** Member, Dr. of Eng., Prof., Disaster Prevention Research Institute, Kyoto Univ. (Yoko-oji, Fushimi, Kyoto 612-8235)
}

\begin{abstract}
This paper presents an experimental study on the impacts of weir removal on the upstream channel dynamics in non-uniform sediment beds. It is found that weir removal promotes local scour and sandbar development in upstream channels, which are two dominant processes to be considered prior to any removal action. On the other hand, the mean sediment size and the geometric standard deviation of sediment mixtures are two governing and practical parameters in characterizing the sediment bed non-uniformity when local scour and bar development are concerned. Sand ribbons are observed in non-uniform beds due to sediment sorting and exert great influences on the bar system and the channel morphology.
\end{abstract}

Key Words: Weir removal, non-uniform sediment, sand ribbon, sandbar, local scour

\section{Introduction}

Maintenance and management of aging and/or outdated hydraulic structures such as weirs and dams pose great challenges in scientific research and engineering practice. When a man-made hydraulic structure becomes suffering from loss of original purpose, physical deterioration, risk of failure, negative environmental impact or financial liability, it makes sense to re-examine whether the benefits of the structure still outweight the costs of safety concerns, ecosystem functions and management expenses ${ }^{1}$. If the structure fails to pass the re-examination, it might be removed, especially in case of a weir which is physically smaller and generally exerts less impacts on the channels compared with a large scale dam. Weir removal has garnered considerable attention since several decades before and there have been a significant amount of weir and low dam removal examples all over the world ${ }^{\text {e.g.2)-8) }}$. In recent years, weir removal is also highlighted as a promising method for river environmental restoration. There have been several reports on the environmental and ecological improvements after weir or low dam removals e.g. 4), 5). Unfortunately, despite the rapid growing number of weir and dam removals, scientific knowledge on the post-removal rivers is still fairly poor. Up to now, most of the researches related to weir or dam removals are based on limited field survey and post-removal monitoring e.g. 2),3), 6), 7), the results obtained from which are generally site-specific and problem dependent.

A weir to be removed generally persists for years, hence the river channel typically has adjusted to the altered hydrologic, hydraulic and sediment transport regimes that the weir imposes and the channel is usually in a quasi-equilibrium state. Since the weir blocks the river and causes river water to back up, the upstream and the downstream of the weir usually exhibit completely different sceneries and characteristics, typically in terms of water pool and sediment storage upstream and associated sediment coarsening and bed degradation downstream. Removal of the weir triggers hydraulic and sediment transport processes that propagate both upstream and downstream, with the upstream response driving the downstream one ${ }^{1)}$. The changes in the flow and geographic parameters furthermore exert impacts on the biogeochemistry and stream habitat. Therefore, removal of a weir, like the presence of a weir, represents a disturbance to the river. Moreover, the fluvial process provocated by the weir construction and weir removal may not always be reversible ${ }^{2)}$. It is hence necessary to characterize and quantify the post-removal channel dynamics and underlying processes.

The authors' research group has conducted a series of studies to investigate the upstream river response to weir removals. In particular, the impacts of the flow discharge, flow

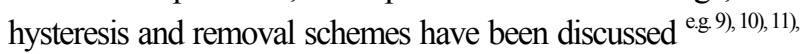
${ }^{12)}$. It is found that dominant discharges of a river are mainly 
responsible for the longitudinal bed features and meso-scale sandbar systems in the upstream channel. After the weir removal, low flows have a potential to trigger minor channels while high flows likely to promote bed forms of dunes/anti-dunes. Irrespective of the initial bed conditions resulted from different flows, the channel beds at the quasi-equilibrium states exhibit similar geographic features after a continuous running of dominant discharges. Removal of the weir structure will result in hydraulic and morphological changes both near and far from the weir. These changes show strong relations with the removal area and the removal shape of the weir section. If a weir pool exists before the removal, the remaining size of the pool is almost inversely proportional to the removal area of the weir section and local scour develops near the weir depending on the removal shape. If sandbar fronts already approach the weir section before the removal, the sandbars will enlarge in wavelength and gradually shift from single system to multiple ones with the increasing of the removal area. The transition of sandbars is a combined result of the upstream propagation of the bed changes near the weir and the downstream development of sandbars. The local changes near the weir are closely related to the removal shape of the structure. According to those observations, it is believed that desirable flow and channel morphology might be achieved if suitable removal schemes were applied. Unfortunately, all those conclusions are based on uniform sediment beds which are rarely encountered in actual rivers. The authors then conduct a numerical simulation to predict the post-removal process of the Katsura River (Japan) after the removal of a weir assuming that the riverbed consists of uniform sediment particles ${ }^{9}$. The results show that the riverbed upstream of the weir almost maintains, even during the flood period. On the other hand, field survey data indicates that the sediment particles behind the weir are much finer than the mean size of the bed materials within that reach and the fine particles are subject to transport after the removal. It is hence suggested that considering the mean size alone shall not be enough for the accurate prediction of the morphological processes and hence flow dynamics in actual river conditions. In fact, as constitute of the bed itself, bed sediment exerts impact not only on the fluvial geomorphology but also on the aquatic ecology since the bed sediment is used directly by periphyton, benthic species, fishes and plants and serves as an indirect indictor for aquatic habitat e.g. 13), 14). Although simple relations between sediment size distributions and biological variables may be misleading but the sediment properties do exhibit close linkage with the distribution and heterogeneity of aquatic species ${ }^{13)}$. Therefore, the sediment heterogeneity should be accounted for prior to any removal action. The impacts of the weir removal on the channel dynamics in non-uniform sediment beds are investigated.

\section{Experiments}

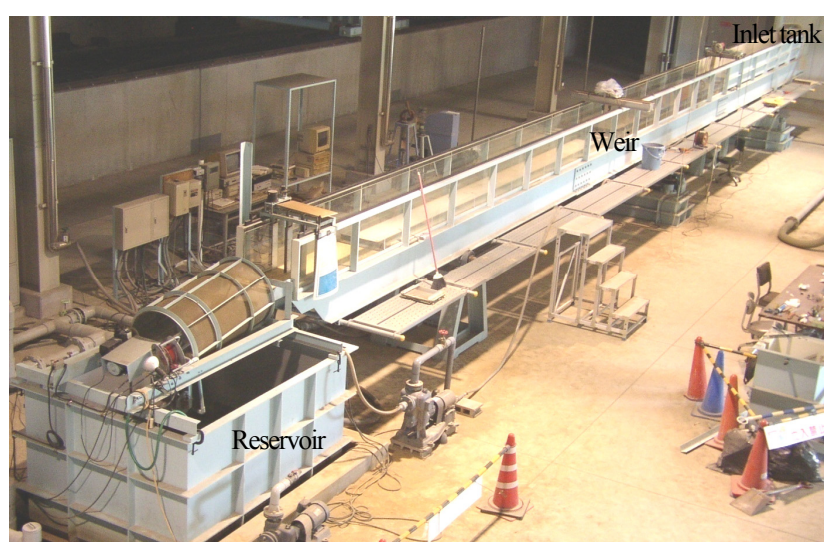

Photo 1 Experiment flume
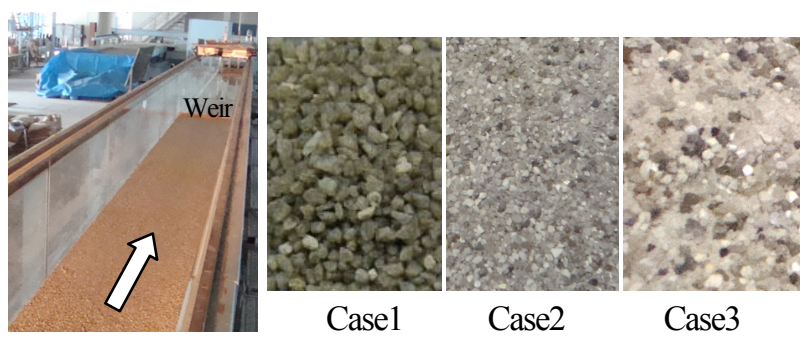

Casel

Case2

Case 3

Photo 2 Movable bed and sediment samples

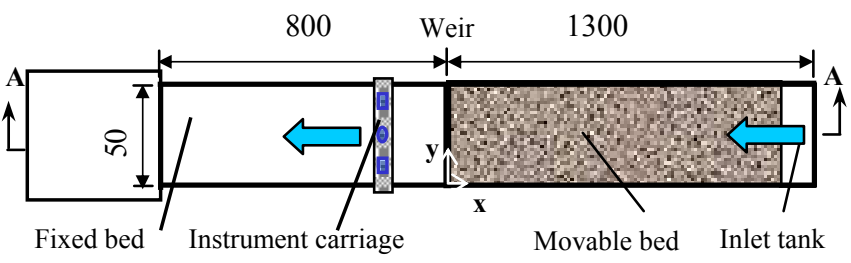

(a) Plan view

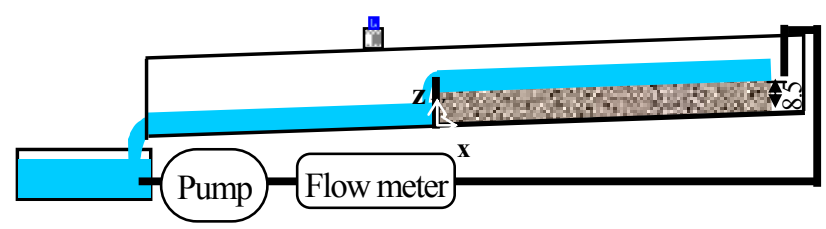

(b) Section A-A

Fig.1 Sketch of experiment setup (Unit: cm)

\subsection{Experiment setup}

A series of experiments are carried out in a straight tilting flume (Photo1) at the Ujigawa Open Laboratory, Disaster Prevention Research Institute, Kyoto University (Japan). The flume has a rectangular transverse cross-section and is $21 \mathrm{~m}$-long, 50cm-wide and $30 \mathrm{~cm}$-deep. An inlet tank and a small reservoir locate at the upstream and the downstream of the flume, and the water in which is re-circulated with a pump and pipe system. Near the junction of the inlet tank and the flume, a steel mesh is installed to inhibit flow concentrations and to minimize the wavy water surface. The slope of the flume is adjustable but has been kept as $1 / 200$ during all the experiments. A model weir of $11.7 \mathrm{~cm}$-height, $50 \mathrm{~cm}$-width and 
$2 \mathrm{~cm}$-thickness is set at $13 \mathrm{~m}$ from the inlet tank. The upstream reach of the weir is covered with $8.5 \mathrm{~cm}$-thick silica sediment, forming a movable bed area as shown in Photo2 and Fig.1.

\subsection{Experiment conditions}

Based on knowledge and experiences from previous studies of the authors e.g. 9), 10), the water discharge in the flume is kept constant as $8.16 \mathrm{l} / \mathrm{s}$, representing a shear stress ratio of $\tau_{*} / \tau_{*_{\mathrm{c}}}=2.0$. Here, $\tau_{*}$ and $\tau_{*_{\mathrm{c}}}$ stand for dimensionless bed shear stress and dimensionless critical shear stress, respectively. This flow condition, applying on the sediment beds in the current experiments, corresponds to a dominant discharge scenario in typical Japanese rivers ${ }^{15}$. The scheme for the weir removal is also prudently selected. In order to understand the processes both near and far from the weir, the weir section is partially removed in terms of both width and height. When the width and height equal to those of the weir section, it turns to a complete removal. As shown in Fig.2, in the middle part across the channel section, the weir is lowered in the vertical plane by $3.2 \mathrm{~cm}$ to the initial flatbed level while maintains a symmetrical shape. Three kinds of sediment beds are prepared for the experiments by mixing different kinds of uniform silica sands. These sands vary a lot in sizes but have the same specific gravity of 2.65. The dry sands are well mixed with prescribed ratios before they are filled to the experiment flume. The typical samples taken at the initial flatbed are shown in Photo2.
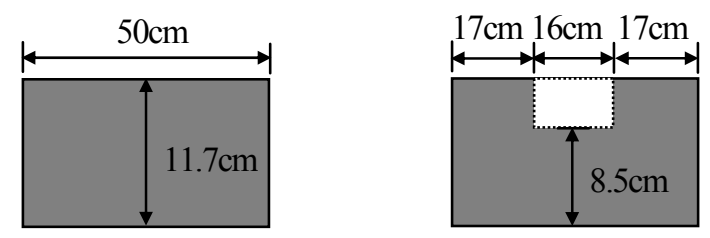

Fig.2 Weir section pre- and post- removal

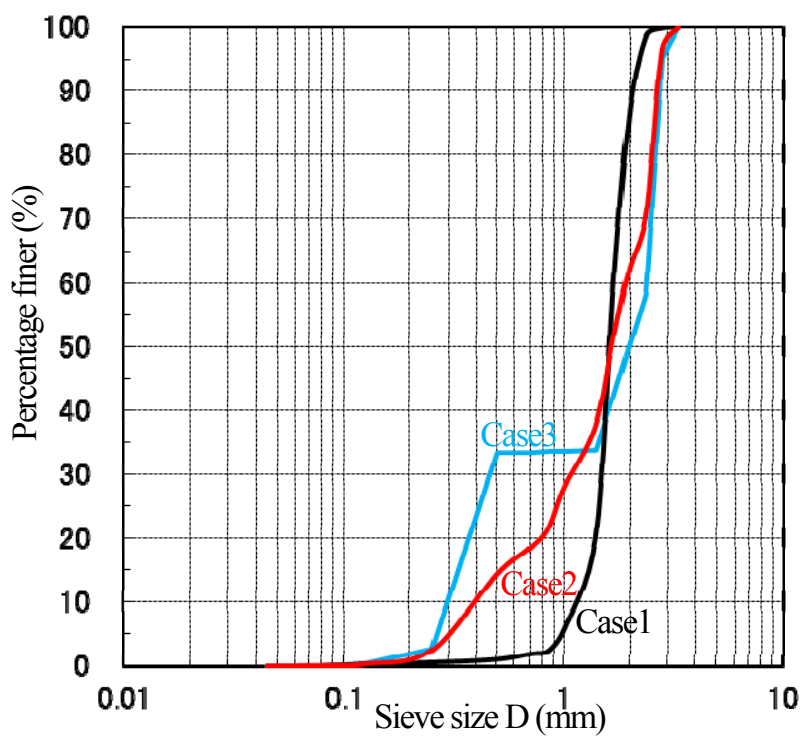

Fig.3 Sieve analysis curves of sediment samples
Table 1 Properties of sediment mixtures

\begin{tabular}{|l|c|c|c|}
\hline & Case1 & Case2 & Case3 \\
\hline Mean grain size $D(\mathrm{~cm})$ & 0.161 & 0.163 & 0.167 \\
\hline Geometric standard deviation $\sigma_{g}$ & 1.200 & 2.151 & 2.953 \\
\hline Uniformity coefficient $C u$ & 1.453 & 5.932 & 8.815 \\
\hline Curvature coefficient $C c$ & 1.286 & 1.968 & 0.168 \\
\hline
\end{tabular}

The sieve analysis curves of the sediment samples taken from the initial flatbeds are plotted in Fig.3. It is evident that the sediment mixtures may be categorized as uniformly graded (Case1), well graded (Case2) and gap graded (Case3), respectively. Despite the great differences in gradation conditions, the sediment in each case shares a similar mean diameter of around $D=0.16 \mathrm{~cm}$ as detailed in Table1. Other important parameters, $\sigma_{g}, C u$ and $C c$ are also listed in the table. Here, $\sigma_{g}$ is the geometric standard deviation and is obtained from $\left(\mathrm{d}_{84} / \mathrm{d}_{16}\right)^{1 / 2}, \mathrm{Cu}$ is the coefficient of uniformity and is defined as $\mathrm{d}_{60} / \mathrm{d}_{10}$ and $\mathrm{Cc}$ is the coefficient of curvature and is expressed by $\mathrm{d}_{30}{ }^{2} /\left(\mathrm{d}_{60} \mathrm{~d}_{10}\right)$.

The hydraulic parameters for the experiments are detailed in Table 2 based on the mean size of the sediment mixtures. Moreover, near the inlet of the flume, the bed elevation is made a little higher than the immediately downstream area as sediment reserves. While during the experiments, additional sediment supply is not made from the upstream.

\subsection{Experiment procedure}

Before each experiment run, the sediment bed surface is levelled with a scraper blade attached to a sliding metal carriage riding on the rails over both sides of the flume. After that, the flume is slowly filled with water from both upstream and downstream. When the desired water depth is achieved upstream of the weir, the downstream water supply is stopped and the pump is set to the desired discharge. The propagation process of sandbars in the channel is memorized if necessary until a quasi-equilibrium condition is reached. The quasi-equilibrium condition is mainly examined based on the propagation characteristics of sandbars and is described in details in the next section. After that, the water level along the centerline of the flume is recorded with a point gauge and the pump is then stopped. Finally, the bed level is measured with a laser displacement meter (Model LK-500, Keyence co., Ltd) and the setup of the pre-removal condition is completed.

Table 2 Hydraulic parameters

\begin{tabular}{|l|l|l|l|}
\hline Discharge $Q$ & $8.161 / \mathrm{s}$ & Grain size $D$ & $0.16 \mathrm{~cm}$ \\
\hline Bed slope $I$ & $1 / 200$ & $u_{*} / u_{*_{\mathrm{c}}}$ & 1.40 \\
\hline Flow depth $h$ & $4.18 \mathrm{~cm}$ & Re. number & 12,651 \\
\hline Mean velocity $U$ & $39.04 \mathrm{~cm} / \mathrm{s}$ & Fr. number & 0.61 \\
\hline
\end{tabular}

$u_{*}=$ friction velocity and $u_{*}=$ critical friction velocity. 


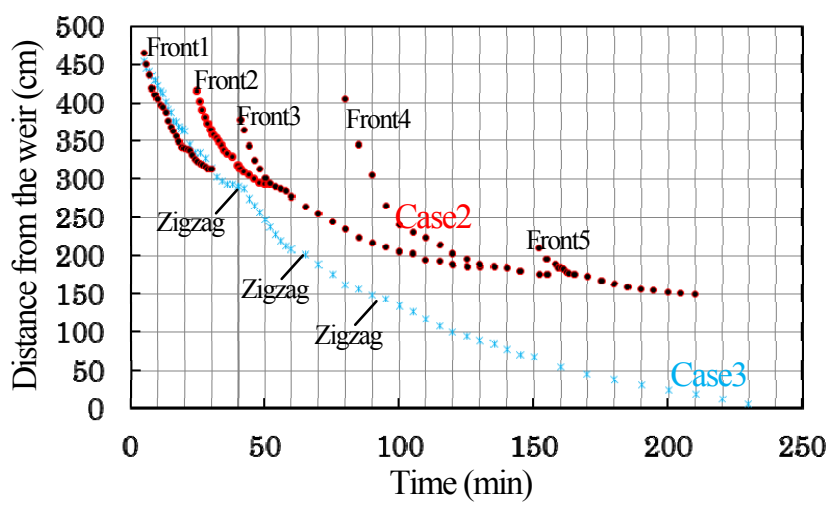

Fig.4 Movement of bar front before weir removal

Before removing the weir, the flume is again filled with water carefully until the desired water depth is achieved. The desired discharge is then set properly and the center part of the weir is removed at the same time. The propagation process of sandbars towards as well as the water level and the bed level at the quasi-equilibrium conditions are investigated following the same procedures as those in the setup of the pre-removal condition.

\section{Results}

\subsection{Temporal variation of bar front}

\section{(1) Pre-removal stage}

Soon after the flow passes the initial flatbed, sediment particles move but are generally confined in the area a little far from the weir at the beginning of each experiment. Sandbar develops quickly and the bar front is obviously distinguishable within several minutes.

In the uniform sediment case (i.e. Case1), the bar front propagates towards downstream with a decreasing propagation velocity and becomes almost stagnant at a location about $4 \mathrm{~m}$ away from the weir after 120min. A stable weir pool forms and a quasi-equilibrium condition is assumed. In the non-uniform sediment cases, however, the situations are a little bit complex.

In the well graded case (i.e. Case2), a race of bar fronts consisting of different-sized sediment particles is observed as shown in Fig.4. Bar front mainly consisting of fine particles appears soon after the start of the experiment and propagates downstream with a decreasing propagation velocity. During the propagation of the bar front, new bar front consisting of coarse sediment forms in the upstream area. The new bar front moves faster than the old one. It overlies on the old one and propagates ever downstream with a decreasing propagation velocity. The new bar front is not the only competitor, a newer bar front composed of coarser particles was born before the first front is colonized by the second one. The newer one propagates downstream much fast and soon replaces the position of the second one. The process is not finished yet, the fourth and the fifth bar fronts emerge one by one, consisting of coarser and coarser sediment particles. The fifth bar front becomes the final winner, it becomes almost stagnant at a place around $1.5 \mathrm{~m}$ away from the weir after 210min. A stable weir pool forms and a quasi-equilibrium condition is assumed. It has to be mentioned that five kinds of relatively uniform sediment particles are used to prepare the mixed sediment in this case, with a mean size of $0.31,0.48 \mathrm{~mm}, 1.03 \mathrm{~mm}, 1.61 \mathrm{~mm}$ and $2.38 \mathrm{~mm}$, respectively. The development of the bar fronts gives evidence on the sediment sorting process of these different size fractions.

In the gap graded case (i.e. Case3), sediment consists of obviously distinguished two size fractions: a fine fraction with a mean size of $0.31 \mathrm{~mm}$ and a coarse fraction with a mean size of $2.38 \mathrm{~mm}$. Ripples of fine sediment particles immediately appear after the start of the experiment. After that, bar front mainly consisting of fine sediment is observed, but the front expands towards downstream and soon becomes invisible to the naked eye. Therefore, the obviously distinguished front consisting of coarse fraction sediment is recorded. It is very clear that zigzags are observed on the path down to the weir as shown in Fig.4, especially in the initial stage. It indicates that the bar front propagates downstream following such a pattern as fast, slowly, fast again and slowly again and this pattern is repeated until the front approaches the weir. In this process, the accumulation of fine sediment plays a crucial role. The existence of thin fine sediment layers reduces the local bed resistance and results in the movement of coarse sediment. In fact, the rapid movement of coarse particles on fine sediment stripes is evidently observed during the experiments. The overlay of fine sediment stripes on the coarse sediment texture is termed sand ribbons in this paper and is discussed later in the context. When the bar front propagates close enough to the weir after $230 \mathrm{~min}$, particles on the upper part of the front is transported over the weir to the downstream by the local flow and the height of the front is lowered. After that, such process is repeated that the sediment from upstream is transported to the front and is carried by the local flow to the downstream of the weir. It has to be mentioned that the bar front maintains a shape like a chin although it expands to the weir section. The experiment finally lasts $300 \mathrm{~min}$ when the sand bar structures and sand ribbons in the flume show insignificant changes.

\section{(2) Post-removal stage}

The weir removal promotes sediment movement both near the weir and in the upstream channel. In the uniform case (i.e. Case1), the bar front propagates downstream immediately after the weir removal and the weir pool shrinks correspondingly. But the propagation velocity of the bar front gradually decreases. After about 1hour, the bar front almost stops with a distance of $1.7 \mathrm{~m}$ away from the weir as shown in Fig.5 and the quasi-equilibrium condition is assumed. 


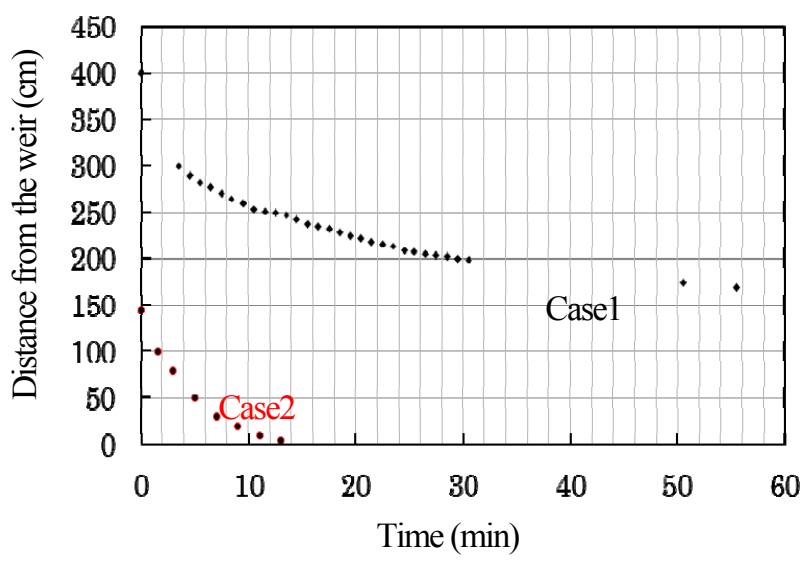

Fig.5 Movement of bar front after weir removal

In Case2, the bar front approaches the weir within 15 minutes as shown in Fig.5 and decreases in height significantly. The bar front meets the local scour near the weir and loses its identity. In Case3, the bar front disappears immediately with the expanding of the local scour after the weir removal. In both Case 2 and Case 3 , after the disappearance of the dominant bar fronts, bars in the more upstream area gradually develop towards downstream. The fine sediment belts, i.e. the sand ribbons, also gradually change with time. The variations of the bars and the sand ribbons are not two independent processes but exhibit certain linkages. The quasi-equilibrium conditions are assumed after a 180min-running and a 90min- running correspondingly based on examinations of the propagation characteristics of the bars and the sand ribbons.

\subsection{Bed deformation}

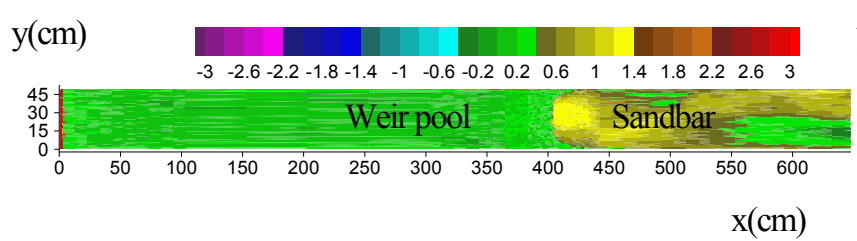

(a) Bed deformation pre-removal (Case1)
The changes of the bed level from the initial flatbed are shown in Fig.6. It is very clear from the pre-removal plots that the impacts of the weir structure on the upstream channels are different depending on the non-uniformity of the channel beds. If simply quantifying the non-uniformity of a bed with the geometric standard deviation $\sigma_{g}$ of the sediment samples, there are some interesting findings. Concerning the weir pool area, it is evident that the weir pool area decreases with the increasing of $\sigma \mathrm{g}$. In the sandbar occupied area, the bed elevation is generally higher if the value of $\sigma_{g}$ is larger. These phenomena demonstrate that sediment particles are more active in non-uniform sediment beds and more non-uniform is the sediment, more active is the bed.

In the uniform sediment case, there is a sharp interface between the sandbar area and the pool area. But in the non-uniform cases, the bed morphology shifts from a bar to a pool gradually through a transition zone. It has to be mentioned that the sediment sizes also show a gradual change in the transition zone according to experimental observations. The transition zone is particularly obvious in Case 2 where 5 kinds of uniform sediment have been mixed. Away from the bar front, bed elevation becomes lower and sediment size becomes finer in the transition zone. The figure also indicates that an alternate bar system is formed in the uniform case. But in the non-uniform cases, it seems that the bar system is a bit difficult to characterize since the topographic features of the sandbars are not easily distinguishable. On the other hand, longitudinal streaks could be observed, especially in Case3. These streaks almost parallel to sand ribbons, indicating that sand ribbons affects not only bed compositions but also bed morphologies.

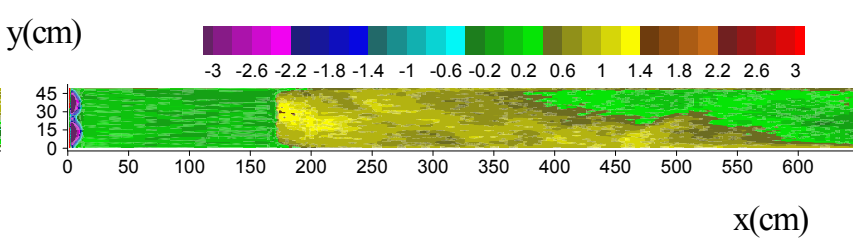

(d) Bed deformation post-removal (Case1)

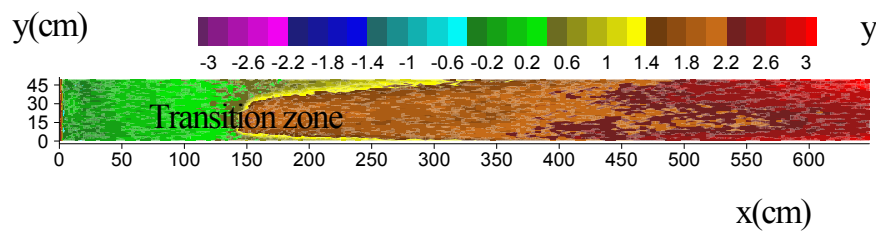

(b) Bed deformation pre-removal (Case2)

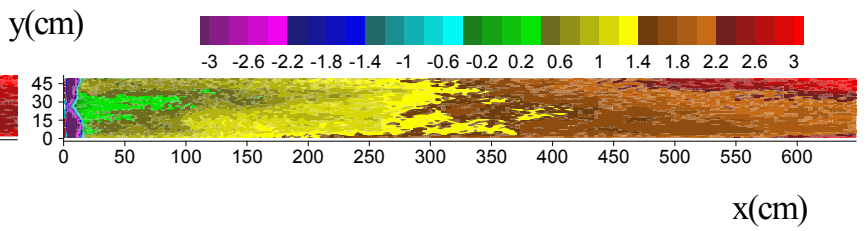

(e) Bed deformation post-removal (Case2)

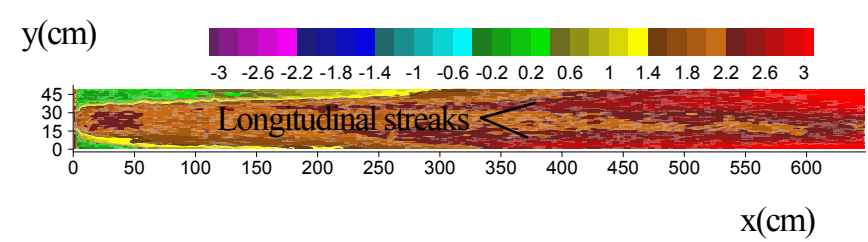

(c) Bed deformation pre-removal (Case3)

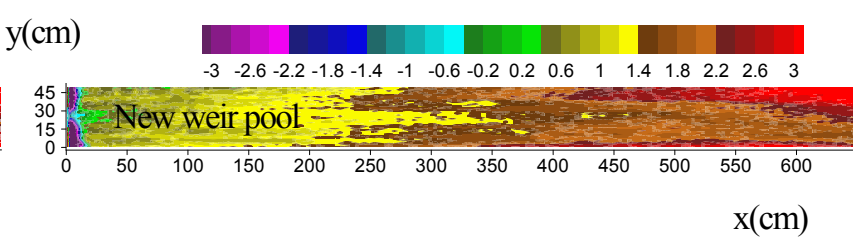

(f) Bed deformation post-removal (Case3)

Fig.6 Bed contour pre- and post- weir removal (Unit: $\mathrm{cm}$ ) 
After the removal of the weir, the sandbar migrates towards downstream and the pool area shrinks in the uniform case. The wavelength of the sandbar is enlarged. In the non-uniform cases, bar fronts approach the weir section and disappear. The pool area is aggraded and the bar area is significantly degraded. In Case 2 and Case3, the bar system is not readily recognizable from the figure since the wave height is very small. However, from the observations in the experiments, it has been found that the bar system in both Case 2 and Case 3 are diagonal bars. It has to be mentioned that the area with an elevation lower than the original weir crest expands towards upstream after the weir removal. This area may be considered as a new type of weir pool although there is no obviously distinguishable bar front to distinguish it from a bar area. The new weir pool is shallower than the original one and the bottom of which is not so flat any more.

\subsection{Local scour near the weir}

It has been found in Fig. 6 that the weir removal promotes local scour near the removed area in all experiment cases. The scour has a potential to undermine the weir structure itself. Furthermore, the scour process interacts with the sandbar development process. Hence it is important to pay much attention to the local scour phenomenon. In order to understand the scour near the removed area, the bed deformation from the initial flatbed near the weir is plotted in details for all experiment cases as shown in Fig.7.

It is clear from Fig.7 that local scour develops in both sides of the centerline of the flume and all the scour holes are very similar in geometries. Although the removed section of the weir is symmetric, the resulted local scour is asymmetric. In fact, it has been observed during the experiments that the scour holes change their geometries according to the development of the sandbars. Since the bar fronts migrate left and right with time, the scour holes shift temporally as well. However, the process is not a random one, it seems that the similar scour patterns appear periodically.

From the bed deformation plots, the dimensions of the scour holes are furthermore extracted as shown in Fig.7 (d). It is found that the maximum scour depth is recorded in Case2, followed by Case 1 and Case3. It indicates that the local scour in a uniform bed is smaller than a non-uniform one. The authors have investigated the local scour around a spur dyke in non-uniform sediment beds ${ }^{16)}{ }^{17}$. It is found that the maximum scour depth in clear water scour conditions decreases with the increasing of $\sigma_{g}$ under a specific discharge if the mean sizes of the sediment mixtures are similar. It implies that the local scour depth in a uniform case will be larger than that in a non-uniform case. It is obvious that the conclusions are not readily extended to this research. The reason is not clear yet, but the most probable one is the differences in the flow approaching the scour hole. Due to the development of upstream bed morphology, the bed elevation and water depth upstream of the local scour are different in different experiment cases. The water depths in the non-uniform cases are much smaller than the uniform one although the flow discharge is the same as will be discussed later. Consequently, a much larger shear velocity ratio $\left(u_{*} / u_{*_{\mathrm{c}}}\right)$ is desirable in the non-uniform case near the weir and it results in possibly lager scour hole there. As the local slope of the scour hole is concerned, it generally follows the sequence of $\alpha>\beta>\gamma$, in which $\alpha, \beta$ and $\gamma$ are local slopes of the scour hole in three representative directions as depicted in the figure. Similar to the scour at spur dykes ${ }^{18)}$, the angles are strongly related to the $3 \mathrm{D}$ vortex systems in the scour hole.

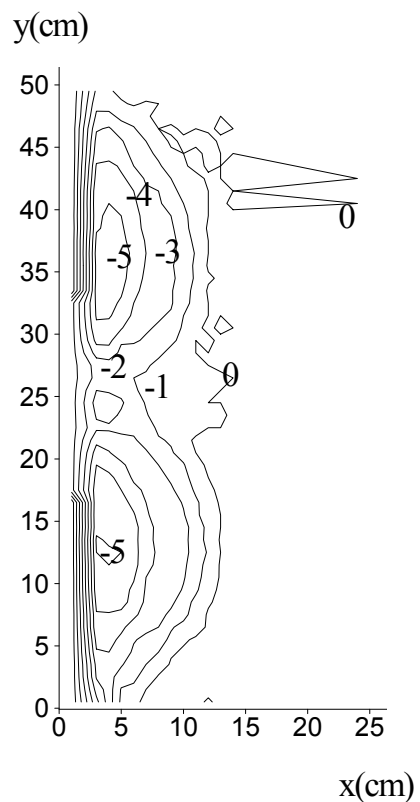

(a) Case1

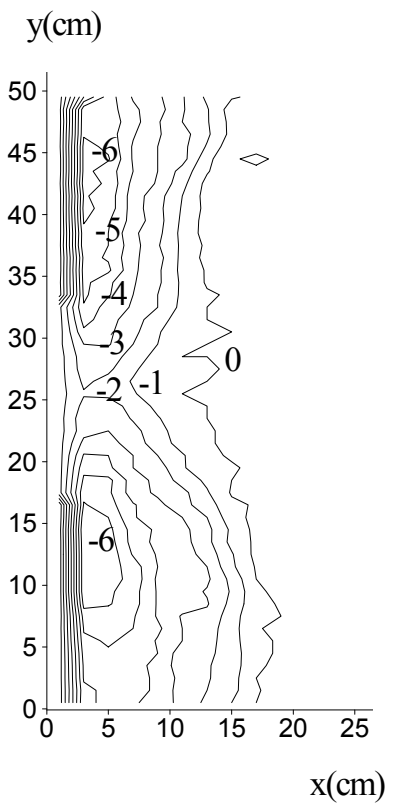

(b) Case2 $\mathrm{y}(\mathrm{cm})$

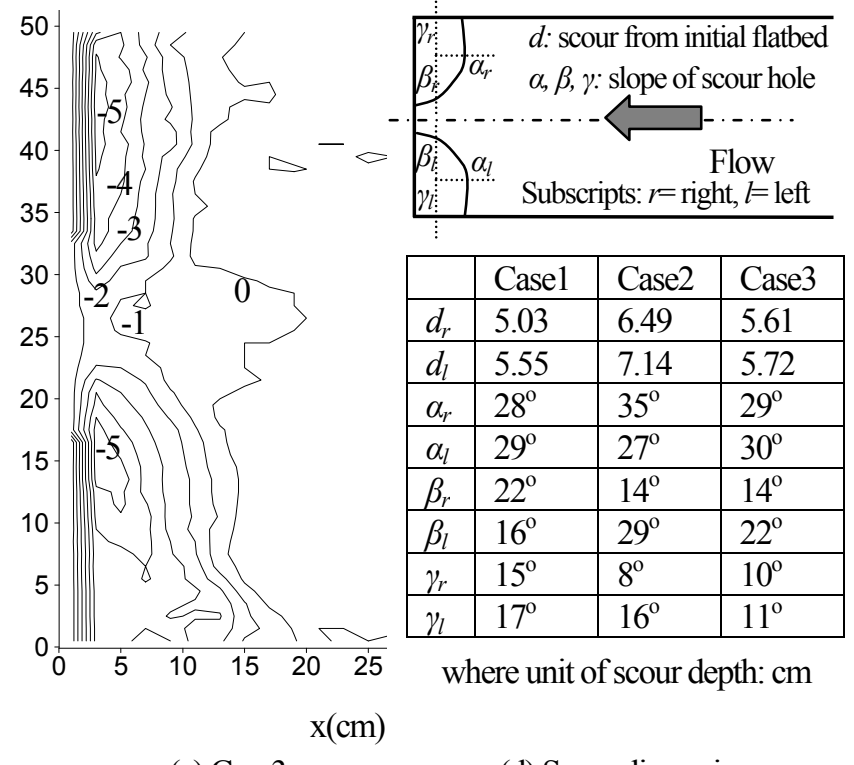

(c) Case3

(d) Scour dimensions

Fig.7 Bed level near the weir after weir removal (Unit: cm) 


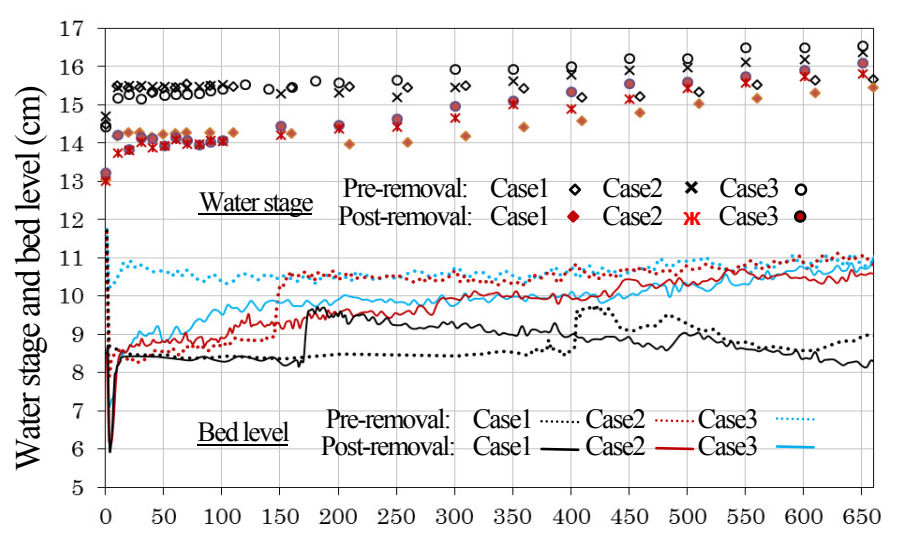

Distance from the weir $(\mathrm{cm})$

Fig.8 Bed elevation and water level along the flume centerline

\subsection{Bed slope and water level}

The water stage and bed level along the centerline of the flume at the quasi-equilibrium condition for each case are plotted in Fig.8.

Bed elevations vary a lot from case to case before the weir removal. Coinciding with the observations in Fig.6, a bigger $\sigma_{g}$ generally corresponds to a higher bed elevation. The dominant bar front at the pre-removal stage is also evident in each case. Immediately upstream of the bar front, the local bed slope becomes negative. Compared with the non-uniform cases, this slope is much steeper in the uniform case. The bar system is recognizable in the uniform case, but is not evident in the non-uniform cases.

After the weir removal, the bar front propagates downstream and the negative slope area is enlarged in the uniform case. In the non-uniform cases, bed slopes become much steeper with the disappearance of dominant sandbar fronts and severe bed degradations. Bed level and bed slope are similar in the area far from the weir in the two non-uniform sediment cases. But near the weir, bed level is higher and bed slope is steeper in Case3 if compared with those in Case2.

Despite the great differences in the bed elevations, the water levels near the weir are very similar in all the experiment cases, indicating that the weir structure plays an important role in controlling the water stage in its neighborhood. In the far upstream area, the impact of the weir becomes weak and the water level profile follows that of the longitudinal bed elevation in each case. Before the weir removal, the slope of the water surface is almost 0 or even negative, corresponding to the weir pool or the negative bed slope area following the dominant bar front. After the removal of the weir, water levels decrease. The decreasing amount is particularly large near the weir due to the significant change in the weir elevation there. Since the decreasing amount gradually increases from the upstream to the downstream, the slope of the water surface becomes steeper than that at the pre-removal stage either near the weir or far from the weir.

The newly formed weir pool area in the non-uniform cases as has been mentioned in the previous context is evident Fig.8. Compared with the sandbar occupied area, the weir pool area shows an obviously steeper longitudinal bed slope.

\subsection{Sand ribbons}

The appearance of sand ribbons is a phenomenon that necessitates special attention for non-uniform sediment beds. Sand ribbons are caused by lateral sediment sorting and are documented to exhibit a strong relation with secondary currents in channels ${ }^{19), 20), 21)}$. During the experiments, the fine sediment stripes which are distinguishable with a naked eye are memorized and are sketched in Fig. 9, together with the bed contours. Photo 3 and Photo4 give visible evidences in Case3. It has to be mentioned that the fine sediment here is not readily defined by a specific grain size. If the particles are obviously finer than the surrounding ones, they are termed fine sediment. Moreover, sediment particles in sand ribbons are not necessarily uniform.

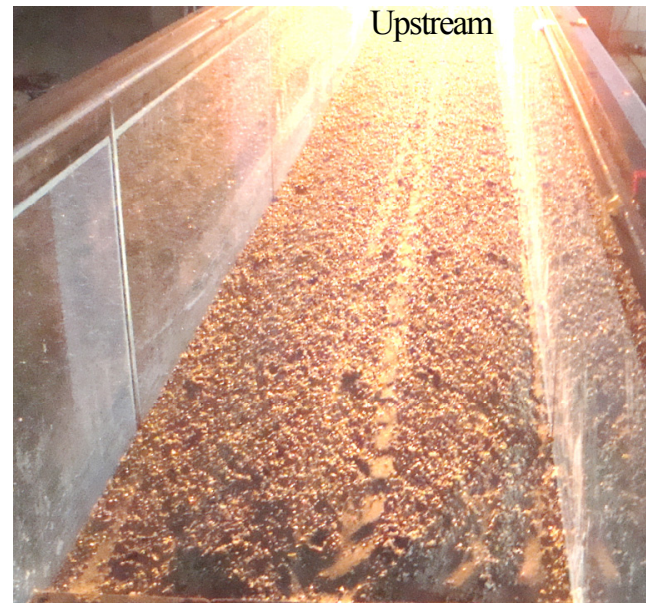

Photo 3 Sand ribbons in Case3 (pre-removal)

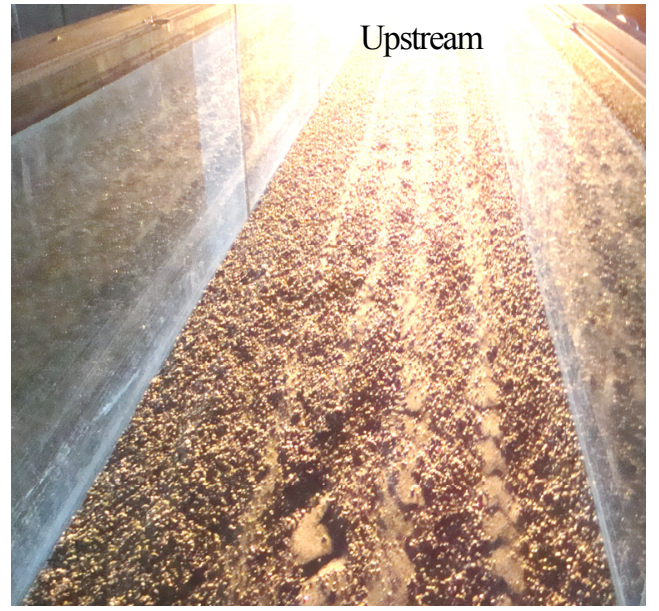

Photo 4 Sand ribbons in Case3 (post-removal) 
In the experiments, it has been noted that the sand ribbons in Case 3 are more evidently distinguishable than those in Case2. If one compares the sand ribbons before the weir removal and after the weir removal in Fig.9, it is clear that in both cases the number of sand ribbons increases after the removal in the downstream part. In the upstream area, however, completely inverse trends are observed. If Case 2 is compared with Case3, it is found that the width of each sand ribbon in Case 2 is a little bit wider than those in Case 3 in the downstream part. Since secondary flows are mainly responsible for the formation of sand ribbons, the width and the number of the sand ribbons are dependent on the strength of the secondary flows and the sizes of sediment particles to be transported. The differences of the sand ribbons in the downstream and upstream area suggest that the weir removal has different impacts on the flow structure in area far and near from the weir. On the other hand, the differences of the ribbons in Case 2 and Case 3 demonstrate that the bed compositions influence a lot on the final appearance of the sand ribbons.

The sand ribbons are not longitudinally parallel to the side of the flume, they adapt themselves at some places where the bed elevation exhibits certain changes. Since local changes in the bed configuration easily trigger and/or alter secondary flows, it may be concluded that the distribution of sand ribbons is affected by the propagation of the sandbar system. However, it has to be mentioned that the secondary flows have a lot of origins such as those due to the inhomogeneity of turbulence, the gradient in channel geometry and the difference in bottom roughness. The formation of the sand ribbons itself results in changes in bottom roughness and flow structures, and which on the other hand exerts impact on the development of sandbars. This phenomenon is particularly evident in Case3. It probably implies that the role which the sand ribbons play becomes more important if the sediment mixtures becomes more non-uniform.

\section{Discussions}

The results obtained from the experiments demonstrate that the presence/removal of a weir structure exerts great impacts on the upstream channel dynamics. These impacts differ a lot in a uniform sediment bed and in a non-uniform sediment bed. As far as the impacts of the weir removal on the upstream channel dynamism are concerned, the following parameters and processes are considered to be of great importance.

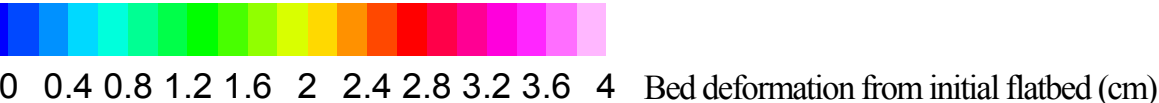

$\mathrm{y}(\mathrm{cm})$
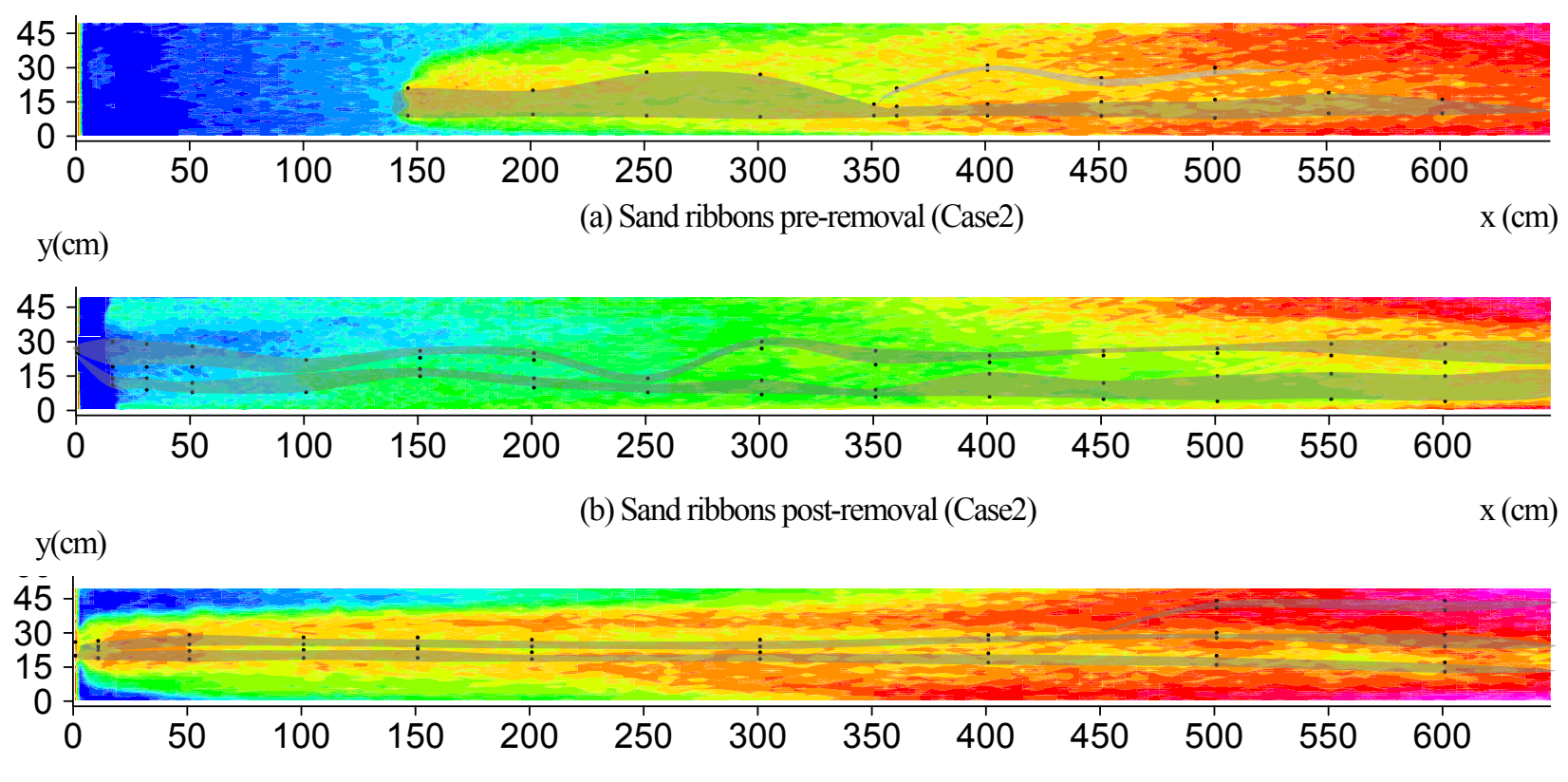

(c) Sand ribbons pre-removal (Case3)

$\mathrm{x}(\mathrm{cm})$

$$
\mathrm{y}(\mathrm{cm})
$$

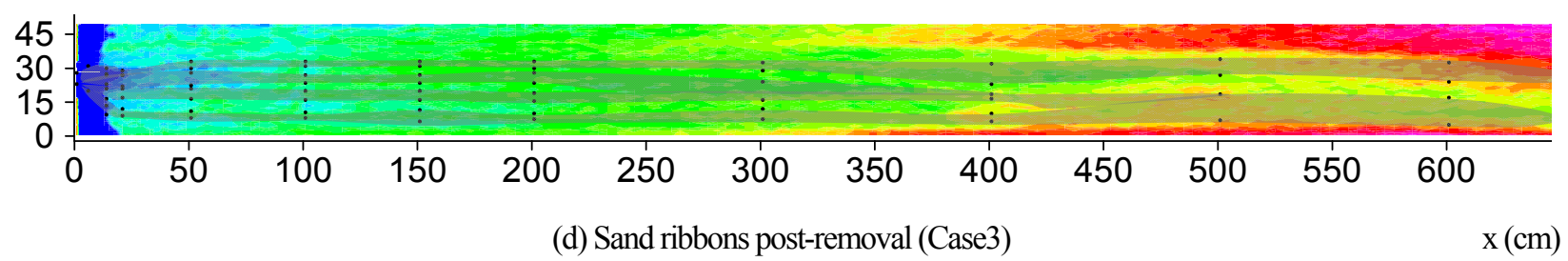

Fig.9 Sand ribbons in non-uniform beds (background maps show bed deformation from initial flatbed) 
There are several important parameters to characterize the non-uniformity of sediment mixtures. In this paper, the mean sediment size $D$, the geometric standard deviation $\sigma_{g}$, the coefficient of uniformity $C u$ and the coefficient of curvature $C_{c}$ are selected for analyses. It may be concluded from the experimental results that $\sigma_{g}$ is the most dominant parameters to characterize the responses of the upstream channel to a weir removal action if the sediment mean diameter is kept constant. The mean diameter $D$ and the parameter $\sigma_{g}$ may be used as simple indicators for the sediment non-uniformity. Moreover, the parameter $\mathrm{Cu}$ is equivalent to the parameter $\sigma_{g}$ to some extent. The role that the parameter $C c$ plays is not evidently confirmed for the time being and more experiments are needed in the near future.

Weir removal exerts impacts both near the weir and far from the weir in the upstream channel. The impacts are mainly in terms of local scour and sandbar development as well as their interaction. In general, more non-uniform the sediment mixture is, more actively the sandbar develops and more limited the local scour expands. However, the interaction between the scour and bar development may influence the final results. The propagation of the bar system affects the local scour process by altering the hydraulic/morphological conditions immediately upstream of the scour area such as the water depth, flow velocity, sediment inflow, bed level and probably sediment properties. On the other hand, the scour process exerts impacts on the bar development by influencing downstream boundary conditions of the channel such as the water stage, channel thalweg and local bed slope. It is noted that the influence of the sandbar propagates towards downstream, while that of the scour propagates towards upstream. Hence, there exist temporal and spatial differences in the responses of the channel during their propagation and the responses may become very complex when the two propagation processes meet.

The experimental observations and quantifiable data indicate that the sediment sorting process is an important phenomenon in non-uniform sediment beds. Sediment particles of different sizes exhibit different mobility under specific flow conditions and sorting processes take place. The dominant flow and the secondary flow trigger sediment sorting in different ways and as a result, sorting processes are found both longitudinally and laterally. Sediment sorting processes pose impacts on both the channel geometry and the bed resistance and which furthermore influences the flow structure. Consequently, bed morphology in a non-uniform bed exhibits quite different features from that of a uniform one. The experimental results indicate that the topographic patterns of sandbars in a non-uniform bed are more irregular than a uniform one and are sometimes not unambiguous determinable due to the sediment sorting in the dominant flow direction and the formation of sand ribbons. Although more quantitative information is needed to understand the weir removal impacts on sediment sorting process, it is evidently confirmed that the weir removal will likely enhance the lateral sediment sorting process according to the changes in the properties of the sand ribbons.

\section{Conclusions}

A series of experiments on the upstream channel response to partial removal of a weir structure have been conducted.

Under the current experimental conditions, weir pool forms in the back water area after the construction of the weir. The pool area and the pool water depth decreases with the increasing of sediment non-uniformity. The weir pool suffers from severe changes after the weir removal and significant attention should be paid to its changes. The pool area will decrease if the sandbar front does not approach the weir section. On the other hand, the weir pool area may expand if the sandbar front is washed away.

Weir removal promotes local scour near the removed section and bar development in the upstream channel. The two processes dominant the hydraulic and morphological processes in the channel. Both the local scour and bar development are strongly related to sediment non-uniformity. Moreover, sand ribbons appear in non-uniform sediment beds as a result of lateral sediment sorting, which furthermore promote coarse sediment movement and the development of sandbars and hence exert impacts on the flow structure.

In order to obtain a clearer image on the consequences of weir removal, more detailed information on the relationship between the distribution of sediment particles on the bed surface and the bed morphology is to be explored based on analyses of sediment samples taken from representative points. Moreover, the distribution of sand ribbons and its relation with the corresponding flow structure is to be clarified in the near future.

\section{Acknowledgements}

This research is financially supported by Grant-in-Aid for Scientific Research (C), MEXT, Japan (PI: Dr. Y. Muto, Grant No.22560511) and JSPS Asia-Africa Science Platform Program (Coordinator: Dr. H. Nakagawa).

\section{References}

1) Doyle, M.W., Stanley, E.H., Harbor, J.M. and Grant, G. S., Dam removal in the United States: emerging needs for science and policy, EOS Transactions, $A G U, 84(4)$, pp.29-33, 2003.

2) Doyle, M.W., Stanley, E.H., Orr, C.H., Selle, A.R., Sethi, S.A. and Harbor, J.M., Stream ecosystem response to small dam removal: lessons from the Heartland, Geomorphology, 71, pp. 227-244, 2005. 
3) Kibler, K. M., Tullos, D. D. and Kondolf, G. M., Learning from dam removal monitoring: challenges to selecting experimental design and establishing significance of outcomes, River Research and Applications, doi: 10.1002/rra.1415, 2010.

4) Woo, H., Trends in ecological river engineering in Korea, Journal of Hydro-environment Research, doi: 10.1016/j.jher. 2010.06.003, 2010.

5) De Leaniz C.G., Weir removal in salmonid streams: implications, challenges and practicalities, Hydrobiologia, 609, pp. 83-96, 2008

6) Rumschlag, J.H. and Peck, J.A., Short-term sediment and morphological response of the middle Cuyahoga River to the removal of the Munroe Falls Dam, Summit County, Ohio, J. Great Lakes Res. 33 (Special Issue 2), pp.142-153, 2007.

7) Wildman, L.A.S. and MacBroom, J.G., The evolution of gravel bed channels after dam removal: case study of the Anaconda and Union City Dam removal, Geomorphology, 71, pp. 245-262, 2005.

8) Walter, C. and Tullos, D.D., Downstream channel changes after a small dam removal: using aerial photos and measurement error for context; Calapooia River, Oregon, River Research and Applications, 26, pp. 1220-1245, 2010.

9) Zhang, H., Kanda, K., Muto, Y. and Nakagawa, H., Morphological response of river channel due to weir reconstruction, Proc. $4^{\text {th }}$ International Conference on Scour and Erosion, Tokyo, Japan, Nov.5-7, 2008. (CD-ROM)

10) Zhang, H., Nakagawa, H., Muto, Y. and Kanda, K., Numerical simulation of bed evolution process due to weir reconstruction, Proc. 33 ${ }^{\text {rd }}$ IAHR Congress, Aug.9-14, Vancouver, BC, Canada, 2009. (CD-ROM)

11) Muto, Y., Kanda, K., Zhang, H. and Nakagawa, H., An experimental study on upstream bed response due to falling works improvement, Proc. 33 ${ }^{\text {rd }}$ LAHR Congress, Aug.9-14, Vancouver, BC, Canada, 2009. (CD-ROM)

12) Muto, Y., Kanda, K. and Zhang, H., Bed evolution process after dam removal in the upstream reach, Proc. 11st International Symposium on River Sedimentation, Sep.6-9, Stellenbosch, South Africa, 2010. (CD-ROM)

13) Shields, Jr. F.D. and Milhous, R.T., Sediment and aquatic habitat in river systems, ASCE Task Committee on Sediment Transport and Aquatic Habitats, Sedimentation Committee, Journal of Hydraulic Engineering, ASCE, 118(5), pp.669-687, 1992

14) Milhous, R.T., Modeling of instream flow needs: the link between sediment and habitat, River Research and Applications, 14, 79-94, 1998

15) Yamamoto, H., Alluvial River Dynamics: Perspective of Sediment Environment, Sankaido Press, 1997 (in Japanese)

16) Zhang, H., Nakagawa, H. and Mizutani, H., Bed variation around spur dyke under non-uniform sediment transport, IAHR-APD 2010, Feb.21-24, Auckland, New Zealand (CD-ROM)

17) Zhang, H., Nakagawa, H. and Mizutani, H., Non-uniform sediment transport around a spur dyke, Proceedings of the International Symposium on Water and Sediment Disasters in East Asia, March23-25, Kyoto, Japan, pp. 96-107, 2010

18) Zhang, H., Nakagawa, H., Kawaike, K. and Baba, Y., Experiment and simulation of turbulent flow in local scour around spur dyke, International Journal of Sediment Research, .24(1), pp. 33-45, 2009.

19) McLean, S.R. The role of non-uniform roughness in the formation of sand ribbons, Marine Geology, 42, pp. 49-74, 1981.

20) Tsujimoto, T., Formation of longitudinal stripes due to lateral sorting by cellular secondary currents, Annual Journal of Hydraulic Engineering, JSCE, 33, pp. 403-408, 1989. (in Japanese)

21) Colombini, M., Turbulence-driven secondary flows and formation of sand ridges, Journal of Fluid Mechanics, 254, pp. 701-719, 1993.

(Received: March 8, 2011) 